\title{
The effect of gradual temperature increase on oxygen consumption rates by three species of carp fishes (Cyprinidae)
}

\author{
Jabbar K. Abdul-Hassan \\ Department of fisheries and water resources \\ College of Agriculture- University of Basra- Basra-Iraq
}

\begin{abstract}
The effect of gradual temperature increase on oxygen consumption by Cyprinus carpio, Ctenopharyngodon idella and Hypophthalmichthys molitrix have been investigated. Studied fishes showed defferent responses as in the following, Cyprinus carpio > Ctenopharyngodon idella $>$ Hypophthalmichthys molitrix $>$ control .

It is obviously clear that fishes in active way were consumed oxygen more than in resting and controls, statistical analysis showed significant correlation among the results
\end{abstract}

Keywords: consumption; thermostat; acclimation; aquaria; activity scope; 


\section{Introduction:}

Elevated temperatures have an influence aquatic organisms directly, as the organisms responded physiologically or behaviorally to the new conditions; or indirectly, as the changed in water temperature influences the water chemical environment. For example, increased temperature reduces the solubility of oxygen in water ${ }^{(3)}$, while ${ }^{(4)}$ pointed that temperature is of such profound importance in chemical and biological processes that the effects of temperature alterations on aquatic biological communities is potentially large. The effects of temperature on the respiratory physiology of fish are particularly important. Increased temperature reduces the amount of $\mathrm{O}_{2}$ available and increases the animal's demand for it and may increase BOD by stimulating more rapid breakdown of organic matter by micro-organisms ${ }^{(11)}$.

The main source of hot water which is discharged from industrial processes and power generation can cause temperature increase in the receiving water of $10^{\circ} \mathrm{C}$ or more ${ }^{(6,8)}$. The effects become more serious during summer months and high salinity values were found near discharge points ${ }^{(\mathbf{1 , 9})}$.

The maximum temperature, which fish can withstand, varies from species to other, and with in a species according to the environmental history of the fish. Generally, fish can acclimate to gradually rising temperatures, so that the lethal temperature depends to some extent on the temperature to which the fish was initially acclimated. Relatively small, sudden changes of temperature, which do not allow the acclimation process to occur, can be more harmful than larger, more gradual changes. ${ }^{(7)}$.

${ }^{(5)}$ reported that at very low temperatures, it has a little scope for muscular activity of any sort, since the efficiency of muscle tissue decreases with increasing temperature.

The aim of the present study to measure oxygen consumption by studying fishes in the laboratory during increase of water temperatures gradually. These measurements were in two fish groups (i.e. the fishes were either in rest or in active conditions in comparison with controls.

\section{Materials and Methods:}

Three fish species from Cyprinidea, common carp (C. carpio, the weight range was 5-6.5 gms.), grass carp ( $C$. idella, the weight range was 6-8 gms.) and silver carp ( $H$. molitrix, the weight range was 5-6.5 gms) have been brought from the ponds of "Marine Science CenterUniversity of Basra". Fifty (50) fishes from each species were acclimated for one week before experiments in glass aquaria $(30 \times 30 \times 60 \mathrm{~cm}$.), electric aerated were used, the temperatures were ranged between 11-12.5 ${ }^{\circ} \mathrm{C}$ during November, 2007 to March, 2008, and $\mathrm{pH}$ values of water ranged 7.4-7.6. The fishes were fed everyday with mixed dry algae and fish muscles during acclimation period.

The mean of body length was $5.5 \mathrm{~cm}$., water temperatures in the control aquaria were measured by normal thermometer $(0-100) \mathrm{C}^{\circ}$, while the water temperature in the test aquaria were gradually increased (reach about $33^{\circ} \mathrm{C}$ ) by using electric thermometer with thermostat type BN-788- China, following the procedure by ${ }^{(6)}$. Fishes in the rest experiments were exposed to gradual increase in temperatures (ranged between $17-33{ }^{\circ} \mathrm{C}$ ), while the fishes in the active experiments were exposed to external effects (by glass pointer) in addition to increase in temperatures. The values of dissolved oxygen (as $\mathrm{mg} / \mathrm{l}$ ) were measured azide modification of Winkler's method (as recommended by ${ }^{(12)}$. Oxygen consumption $\left(\mathrm{mg} \mathrm{kg}^{-1} \cdot \mathrm{hr}^{-1}\right.$, i.e. to calculate 
the weight as $\mathrm{kg}$ and time as an hour) was calculate by a comparison between dissolved oxygen values in the water of rest and active experiments as recommended by ${ }^{(2)}$.

\section{Results:}

The relationship between fish oxygen consumption in both rest and active conditions comparison with controls may be summarized in the following figs.:

Fig. (1) shows oxygen consumptions by Cyprinus carpio in the rest and active experimental fishes. These results have been obtained when the temperature increases gradually from 17.5 ${ }^{\circ} \mathrm{C}$ to $33{ }^{\circ} \mathrm{C}$. The range of oxygen consumption of resting fishes were $25-220 \mathrm{mg} / \mathrm{kg}^{-1} / \mathrm{hr}^{-1}$, while the range in active fishes were $100-410 \mathrm{mg} \cdot \mathrm{kg}^{-1} \cdot \mathrm{hr}^{-1}$.

The maximum values of oxygen consumption were $45-216 \mathrm{mg} \mathrm{kg}^{-1} \cdot \mathrm{hr}^{-1}$ of $C$. idella (fig. 2), while the minimum values were $20-125 \mathrm{mg} . \mathrm{kg}^{-1} \cdot \mathrm{hr}^{-1}$ during active and resting fishes respectively.

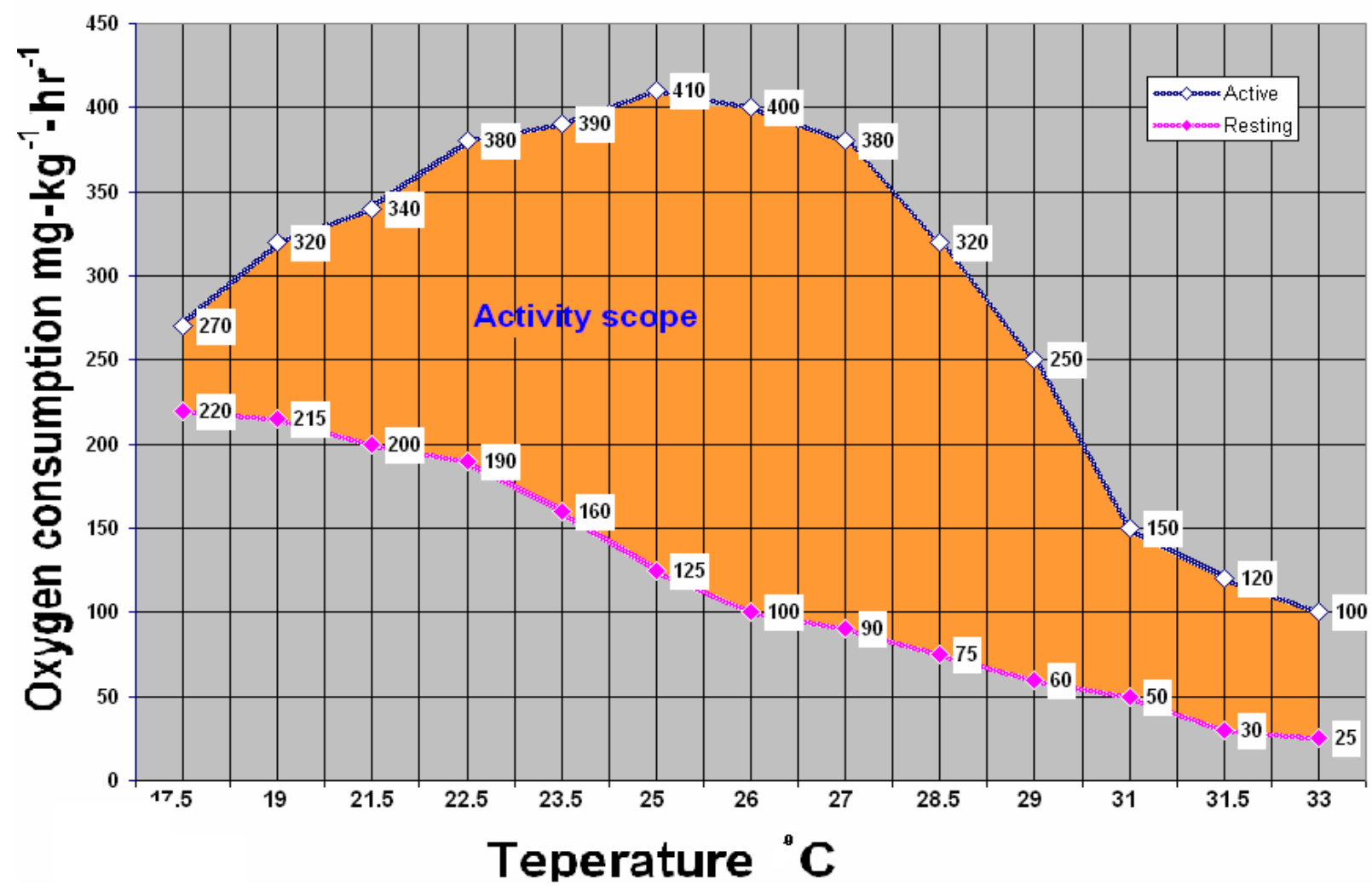

Fig. (1) Activity scope between active and resting fish Breathing of $C$. carpio during temperature rise 


\section{J.Thi-Qar Sci.}

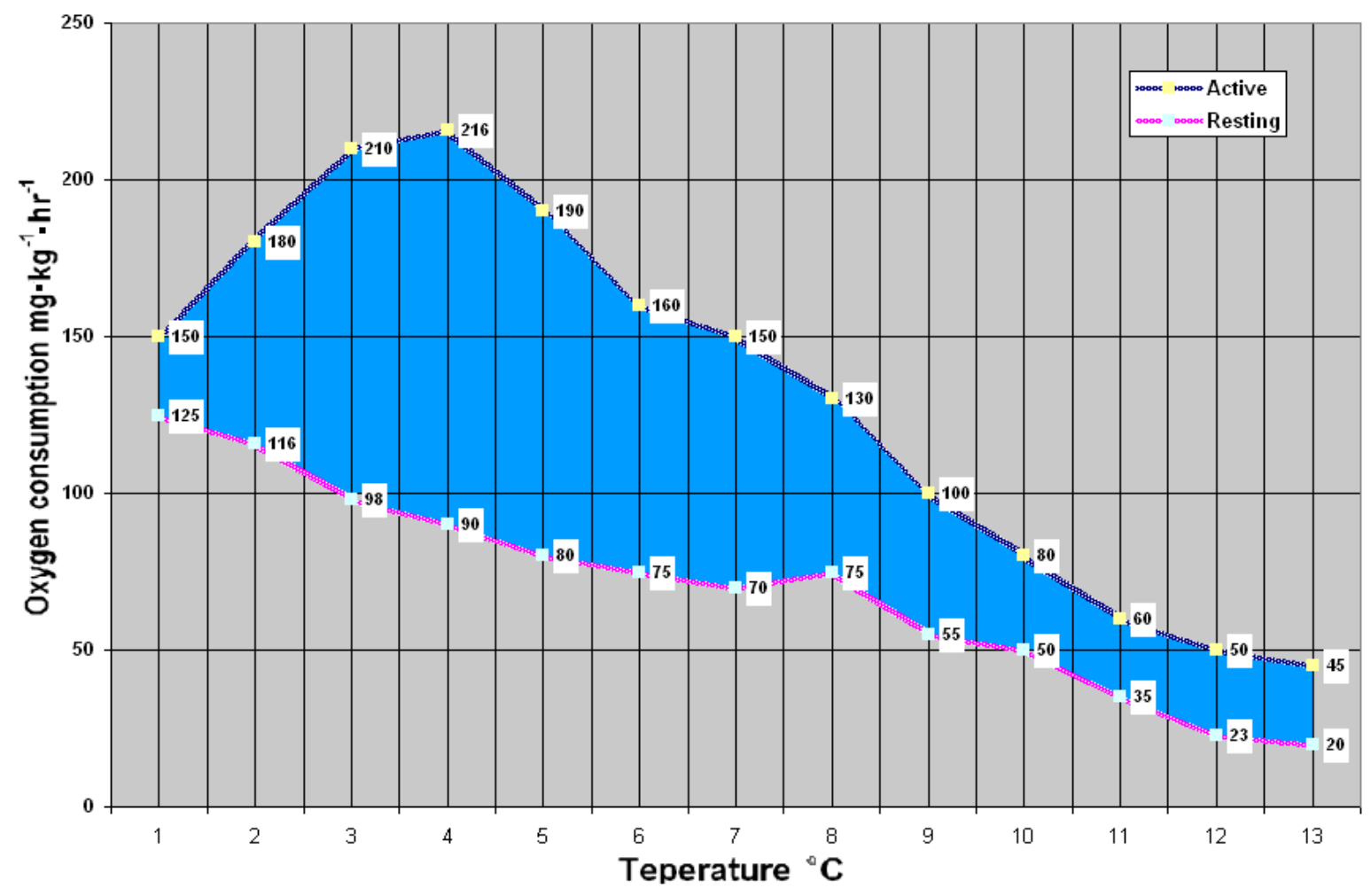

Fig. (2) Activity scope between active and resting fish breathing during of Ctenopharyngodon idella temperature rise

Fig.(3) shows oxygen consumption by active fishes, the maximum values were ranged between $55-165 \mathrm{mg}$. $\mathrm{kg}^{-1} \cdot \mathrm{hr}^{-1} \mathrm{H}$. molitrix, the minimum values of oxygen consumption during resting fishes were $39-85 \mathrm{mg}$. $\mathrm{kg}^{-1} \cdot \mathrm{hr}^{-1}$. Fig. (4) shows the values of oxygen consumption during resting time for all tested fishes, while fig. (5) shows the values of oxygen consumption by three studied fishes during active experiments.

Fig. (6) shows the values of oxygen consumption of $C$. carpio comparison with controls in both active and resting period, while fig. (7) shows oxygen consumption of $C$. idella during active and resting period in comparison with controls.

Fig. (8) shows oxygen consumption by $H$. molitrix during active and resting periods, fig. (9) shows the comparison between oxygen consumption by three fish species for resting and active values. 


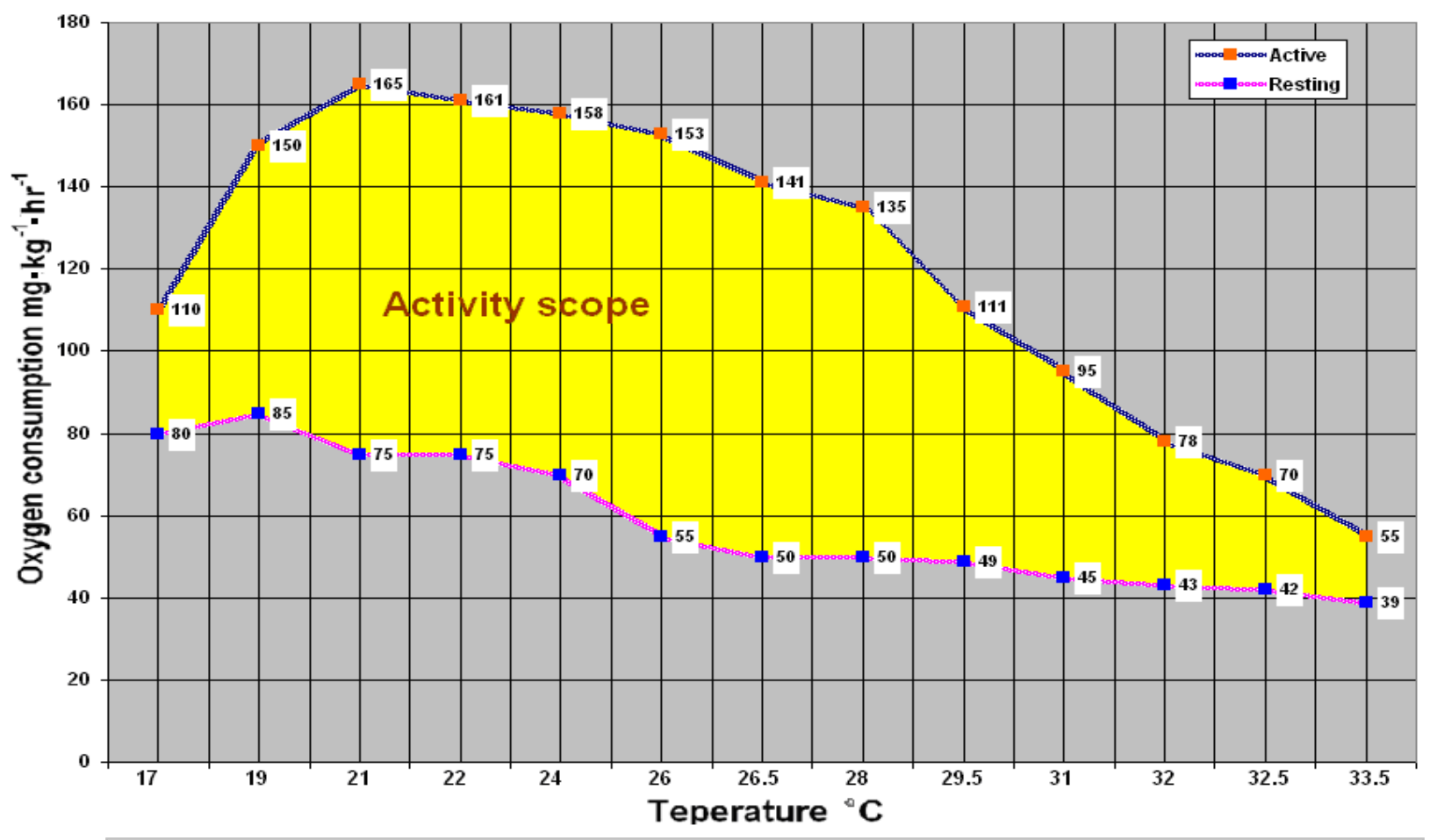

Fig. (3) Activity scope between active and resting fish breathing for $H$. molitrix during temperature rise

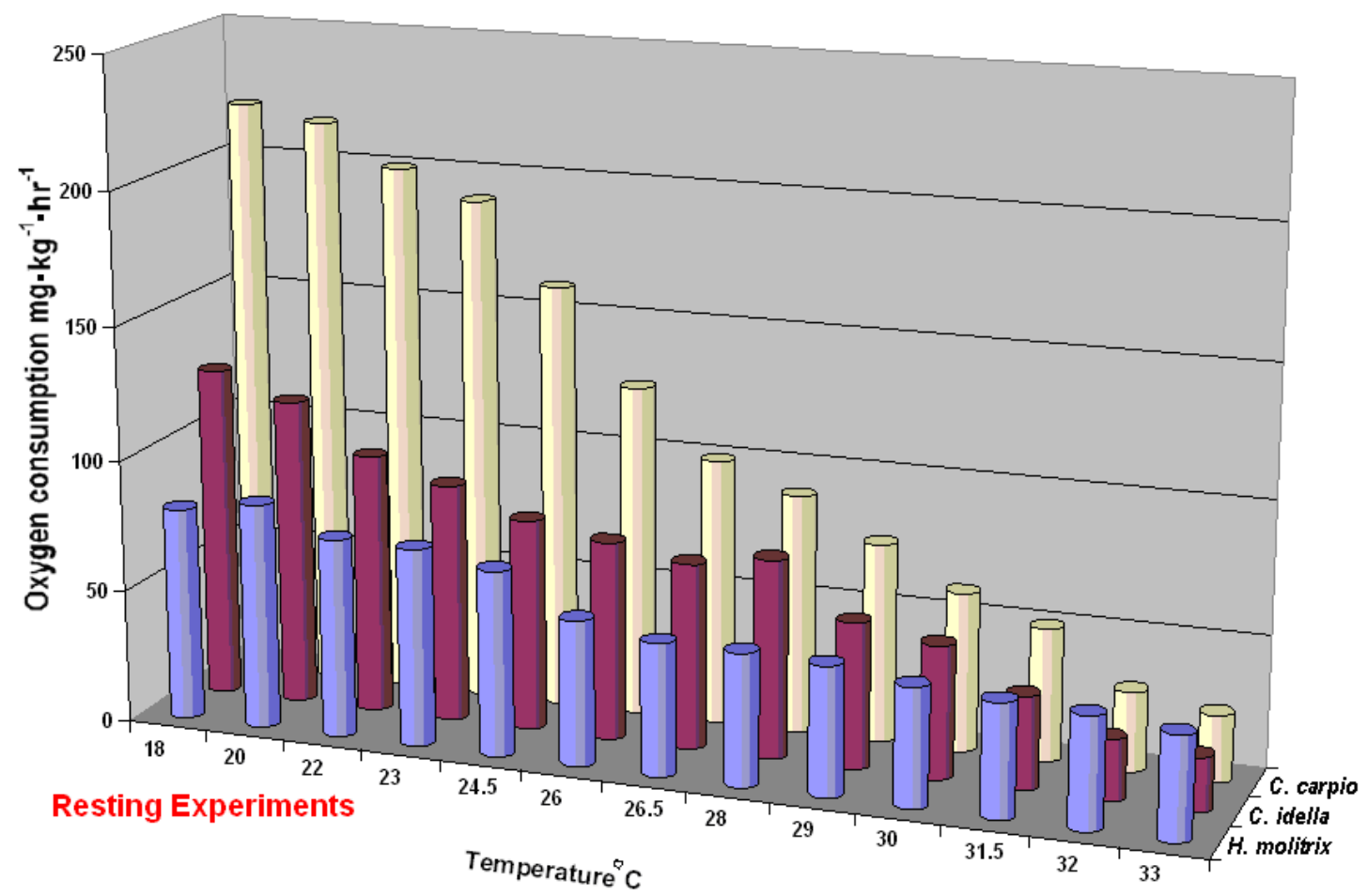

Fig. (4) Shows the values of oxygen consumption by experimental fishes during rest and temperature rise 


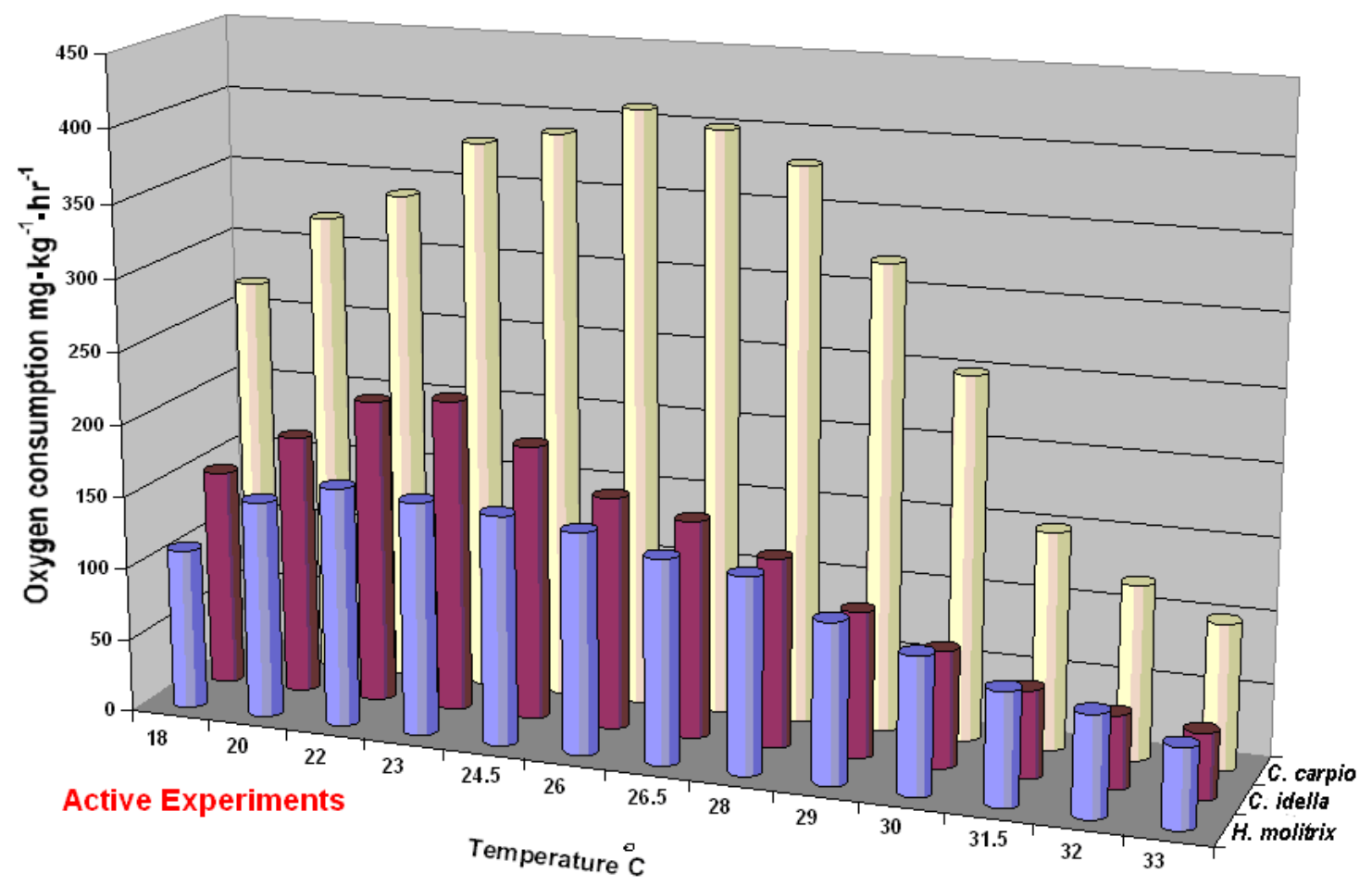

Fig. (5) Shows the values of oxygen consumption by experimental fishes during active and temperature rise
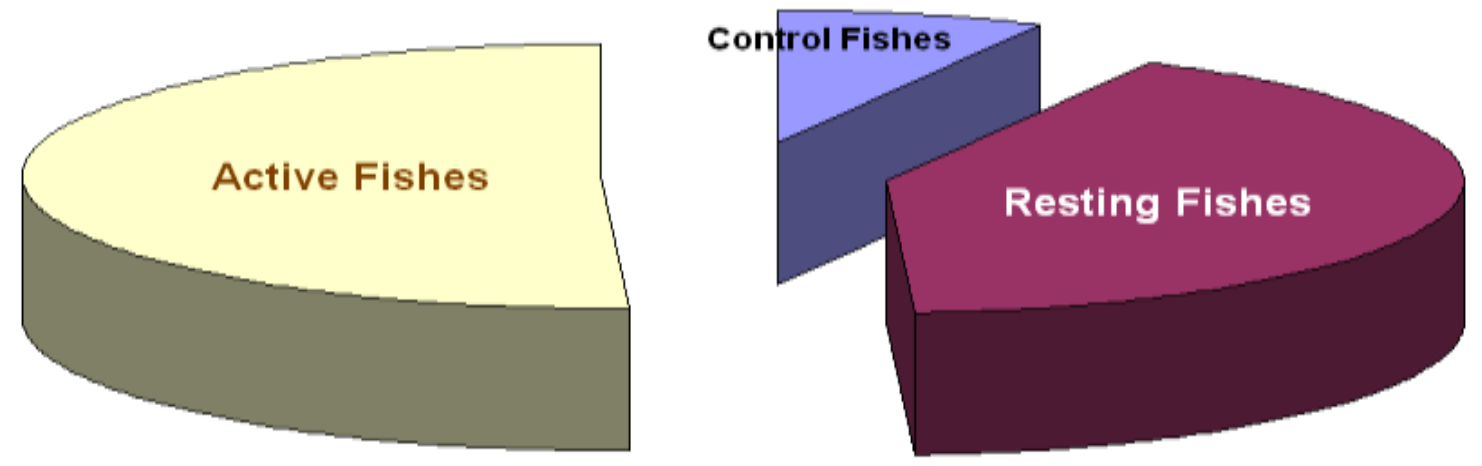

Fig. (6) Shows oxygen consumption by $C$. carpio comparison With the controls during temperature rise 

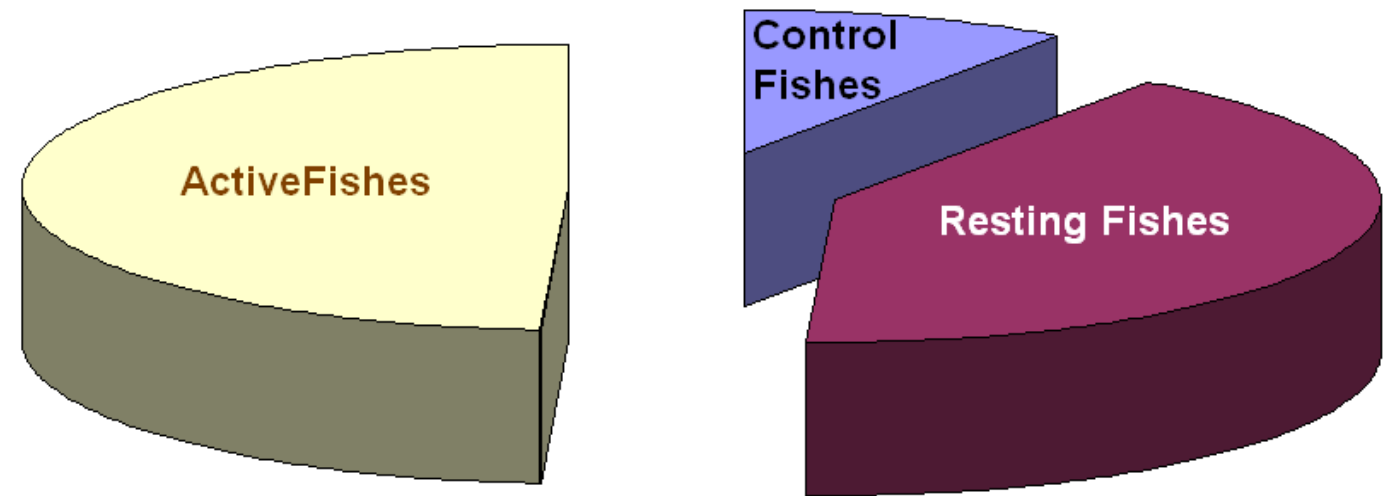

Fig. (7) Shows oxygen consumption by $C$. idella comparison with the controls during temperature rise.
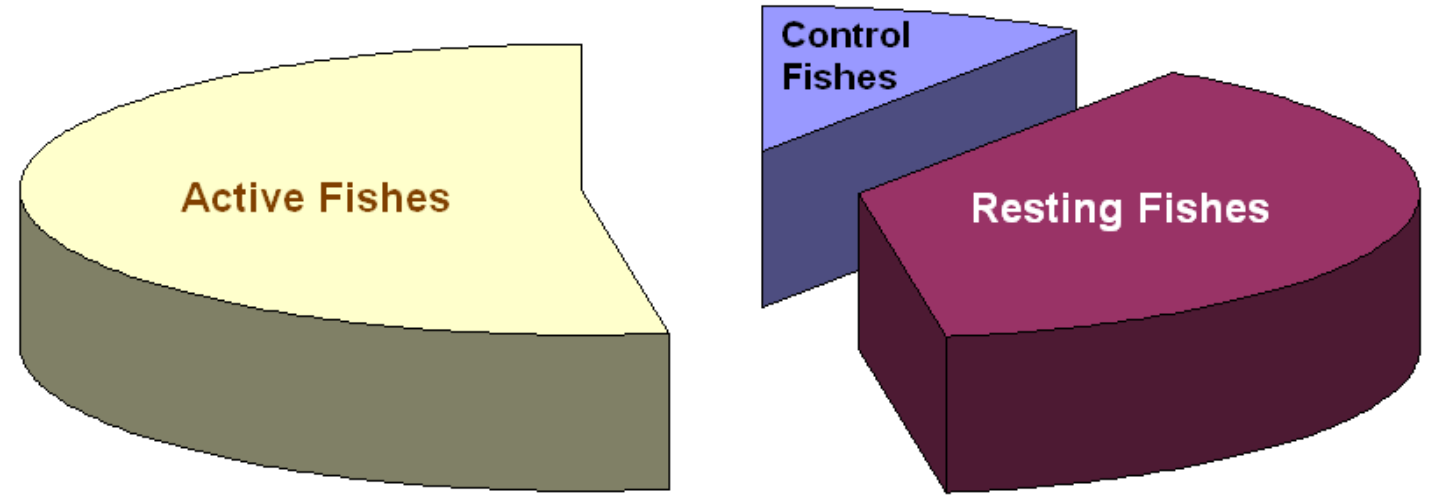

Fig. (8) Shows oxygen consumption by $\boldsymbol{H}$. molitrix comparison with the controls during temperature rise

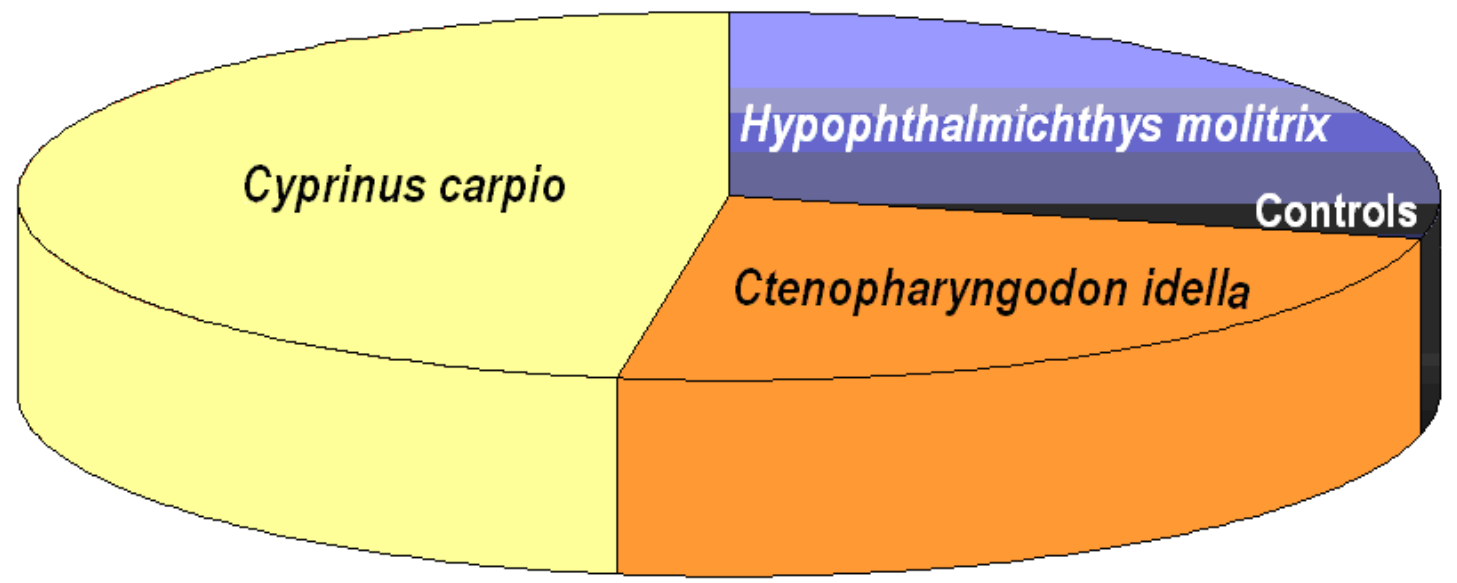

Fig. (9) Comparison between oxygen consumption during active and rest periods for each species with the controls 
Statistical analysis was carry out using "SPSS" programs, the analysis of oxygen consumption values for $C$. carpio during rest and active fishes comparison with controls showed high significance $(\mathrm{p}<0.05)$ and correlation was $\mathrm{r}=0.922$. oxygen consumption by $C$. idella was high also; especially in the case of active fishes compared with resting and the control fishes. The analysis was significant $(\mathrm{p}<0.05)$ and correlation was $\mathrm{r}=0.810$.

Oxygen consumption amount by $H$. molitrix was less in both active and resting fishes in comparison with other two studied species. The relation was insignificant $(p>0.05)$ and the correlation coefficient was $\mathrm{r}=-0.890$.

\section{Discussion:}

The maximum temperature, which fish can withstand, varies from species to species, and within a species according to the environmental history of the fish. Generally, fish can acclimate to gradually rising temperatures for some degree, so that the lethal temperature depends to some extent on the temperature to which the fish was initially acclimated. Relatively small, sudden changes of temperature, which do not allow the acclimation process to occur, can be more harmful than larger, more gradual changes ${ }^{\mathbf{( 1 3 )}}$.

${ }^{(14)}$ mentioned that in practice, the temperature regime, which is favorable for the indefinite survival of the fish, includes a much narrower range of temperatures than that which would allow the survival of the fish under laboratory conditions. This conclusion agrees with the present results concerned with the effects of temperature on oxygen consumption inside laboratory conditions. These effects differ between species and anothers. These results showed wide differences between the amounts of oxygen consumption, common carp ( . carpio) was more resistance than two studied species (fig.1), this is very clear in activity scope compared with those in figs. (2 and 3).

Grass carp (C. idella) showed more resistance as shown in fig. (2) than silver carp ( $H$. molitrix) fig. (3) in the activity scope with increasing temperature. ${ }^{(3)}$ described elegantly and in detail the respiratory predicament of fishes. A fish at rest in well-oxygenated, and water ventilation in the gills was slowly, same results were recorded by ${ }^{(\mathbf{1 0 , 7 , 1 3 , 1 4})}$. Respiratory exchange is efficient, and removes most of the oxygen from the water passing over its gills. If, however, the fish ventilates more quickly, as it must for example if it becomes physically active, the water passing over the gills has less time to equilibrate with the blood, and the efficiency of respiratory exchange drops. Thus, in order to double the rate of oxygen uptake, the fish must double the amount of water pumped over the gills.

\section{Conclusions:}

The oxygen consumption values and activity scope area which belong to the studied fish species were in the order: Common carp $(C$. carpio $)>$ Grass carp $(C$. idella $)>$ Silver carp $(H$. molitrix). The amounts of oxygen consumption by the same species were in the order: Active $>$ resting > control fishes.

\section{References:}

1.Abdul-Hassan,J.K. and Dhia K. Kareem (1998) Synergistic effects of some heavy metals and salinity on survival of Gumbusia affinis. Basrah J. Agric. Sci., Vol.2 (1,2) :71-80.

2.Abel, P. D. 1989. Water pollution biology. Ellis Horwood Limited Publishers. Chichester, Halsted Press, pp 231.

3. Alexander, R. McN (1999) Functional design in fishes. $2^{\text {nd }}$ edn. Huthinson, London. 
4. Brown, V. M. (2007) Concepts and outlook in testing the toxicity of substances to fish. In: Glass, G. E. (ed). Bioassay techniques and environmental chemistry. Science Publishers, Ann Arbor.

5.Cairns, J. Heath, A.G. and Parker, B.C. (2005) The effects of temperature upon the toxicity of chemicals to aquatic organisms. Hydrobiologia, 47:135-171.

6.Castenholtz, R.W. and Wickstrom, C.E.(2000). Thermal stream . In; Whitton, B.A. (ed). River ecology, Blackwell Scientific Publiations, Oxford, 264-285.

7.Davis, J.C.(2003) Sublethal effects of bleached kraft pulp mill effluent on respiration and circulation in sockeye salmon (Oncorhynchus nerka). J. Fish. Res. Bd. Can., 30:369-377.

8.Howells, G.D.(2007) The effects of power station cooling water discharges on aquatic ecology.Wat. Poll. Control, 82:10-17.

9.Hussein, S.A.;I.J.M. Al-Shawi and A.M. Al-Nasir. (2001). Impact of Al-Najebia thermal energy power plant on aquatic ecosystem of Garmat Ali canal. 1.Physico-chemical characteristics, Mar. Mesopo. , 16(2): 517-525.

10. Langford, Terry E. 1999. Ecological Effects of Thermal Discharges. New York: Elsevier Applied Science.

11. Lester, W.F.(2005).Polluted river: River Trent, England. In: Whitton, B.A. (ed). River ecology, Blackwell Scientific Publiations, Oxford, 489-513.

12. Lind, O.T. 1979. Handbook of common methods in limnology. $2^{\text {nd }}$ Eds. London. Biol. Co. St. Louis 199 pp.

13. Varley, M. (2003) British freshwater fishes: Factors affecting their distribution. Fishing News (Books), London.

14. Vigers, G.A. and Mayanard, A.W.(2006) The residual oxygen bioassay: a rapid procedure to predict effluent toxicity to rainbow trout. Wat. Res. 11:343-346.
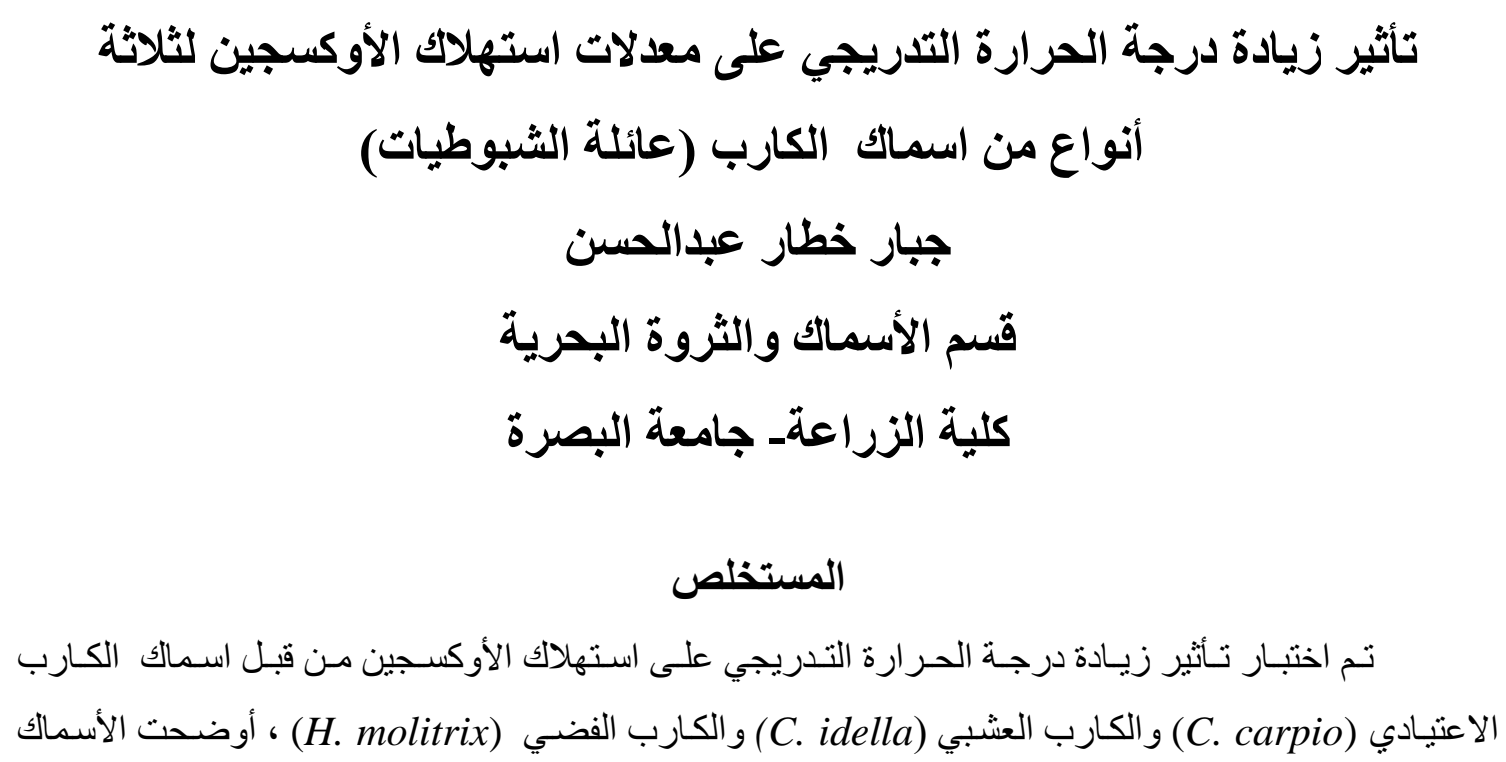

المدروسة اختلافا في الاستجابة وكما موضح بالآتي، Controls > H. molitrix > C. idella > C. carpio.

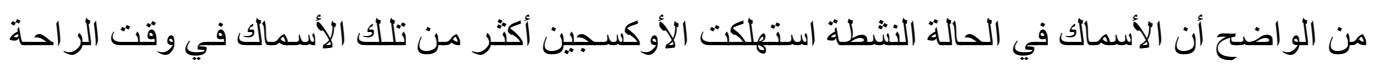
وكذلك لأسماك السيطرة، ونتائج التحليل الإحصائي أظهرت علاقة معنوية في النتائج. 